\title{
Papers
}

\section{Non-invasive positive pressure ventilation to treat respiratory failure resulting from exacerbations of chronic obstructive pulmonary disease: Cochrane systematic review and meta-analysis}

\author{
Josephine V Lightowler, Jadwiga A Wedzicha, Mark W Elliott, Felix S F Ram
}

\begin{abstract}
Objectives To determine the effectiveness of non-invasive positive pressure ventilation (NPPV) in the management of respiratory failure secondary to acute exacerbation of chronic obstructive pulmonary disease.

Design Systematic review of randomised controlled trials that compared NPPV and usual medical care with usual medical care alone in patients admitted to hospital with respiratory failure resulting from an exacerbation of chronic obstructive pulmonary disease and with $\mathrm{PaCO}_{2}>6 \mathrm{kPa}$.

Results The eight studies included in the review showed that, compared with usual care alone, NPPV as an adjunct to usual care was associated with a lower mortality (relative risk 0.41 (95\% confidence interval 0.26 to 0.64$)$ ), a lower need for intubation (relative risk 0.42 (0.31 to 0.59$)$ ), lower likelihood of treatment failure (relative risk 0.51 (0.38 to 0.67$)$ ), and greater improvements at 1 hour in $\mathrm{pH}$ (weighted mean difference 0.03 (0.02 to 0.04$)$ ), $\mathrm{PaCO}_{2}$ (weighted mean difference $-0.40 \mathrm{kPa}(-0.78$ to -0.03$))$, and respiratory rate (weighted mean difference -3.08 breaths per minute $(-4.26$ to -1.89$))$. NPPV resulted in fewer complications associated with treatment (relative risk 0.32 (0.18 to 0.56$)$ ) and shorter duration of stay in hospital (weighted mean difference -3.24 days $(-4.42$ to -2.06$)$ ).

Conclusions NPPV should be the first line intervention in addition to usual medical care to manage respiratory failure secondary to an acute exacerbation of chronic obstructive pulmonary disease in all suitable patients. NPPV should be tried early in the course of respiratory failure and before severe acidosis, to reduce mortality, avoid endotracheal intubation, and decrease treatment failure.
\end{abstract}

\section{Introduction}

Patients with chronic obstructive pulmonary disease (COPD) are prone to respiratory failure, often resulting in admission to hospital. Between a fifth and a third of patients admitted with hypercapnic respiratory failure secondary to acute exacerbation of COPD will die in hospital, despite mechanical ventilation. $^{1-5}$

Conventional treatment aims to ensure adequate continuous oxygenation and to treat the cause of the exacerbation-usually achieved through treatment with bronchodilators, corticosteroids, antibiotics, and controlled oxygen. Traditionally, patients who do not respond to conventional treatment are given invasive ventilation. The procedure of tracheal intubation and assisted ventilation is associated with high morbidity, and it may be difficult to wean these patients from ventilation. ${ }^{67}$ Furthermore, although it is common practice to give intubation and mechanical ventilation, complications can result from the intubation process (damage to local tissue) and during the course of ventilation (pneumonia and sinusitis associated with ventilators), prolonging stay in intensive care..$^{8-11}$

Non-invasive positive pressure ventilation (NPPV) is an alternative treatment for patients admitted to hospital with hypercapnic respiratory failure secondary to acute exacerbation of COPD. ${ }^{12}$ In NPPV the patient receives air or a mixture of air and oxygen from a flow generator through a full facial or nasal mask, and thus ventilation is enhanced by the unloading of fatigued ventilatory muscles. Over the last decade NPPV has been increasingly used as an adjunct treatment in the management of acute exacerbations of COPD, supported by a number of case series and randomised controlled trials..$^{2-413-15}$ However, NPPV is not successful in all cases of acute or chronic respiratory failure in patients with COPD. ${ }^{16}$ Failure rates of between $9 \%$ and $50 \%$ have been reported. ${ }^{17} 18$ We conducted a systematic review of the literature to determine the effectiveness of NPPV in patients with respiratory failure resulting from an acute exacerbation of COPD.

\section{Methods}

\section{Inclusion and exclusion criteria}

Interventions-Trials were considered for inclusion if the intervention was NPPV, applied through a nasal or face mask, in addition to usual medical care. Usual medical care could include supplemental oxygen, antiDepartment of
Respiratory
Medicine, St James's
University Hospital,
Leeds LS9 7TF
Josephine V review is shown on bmj.com 


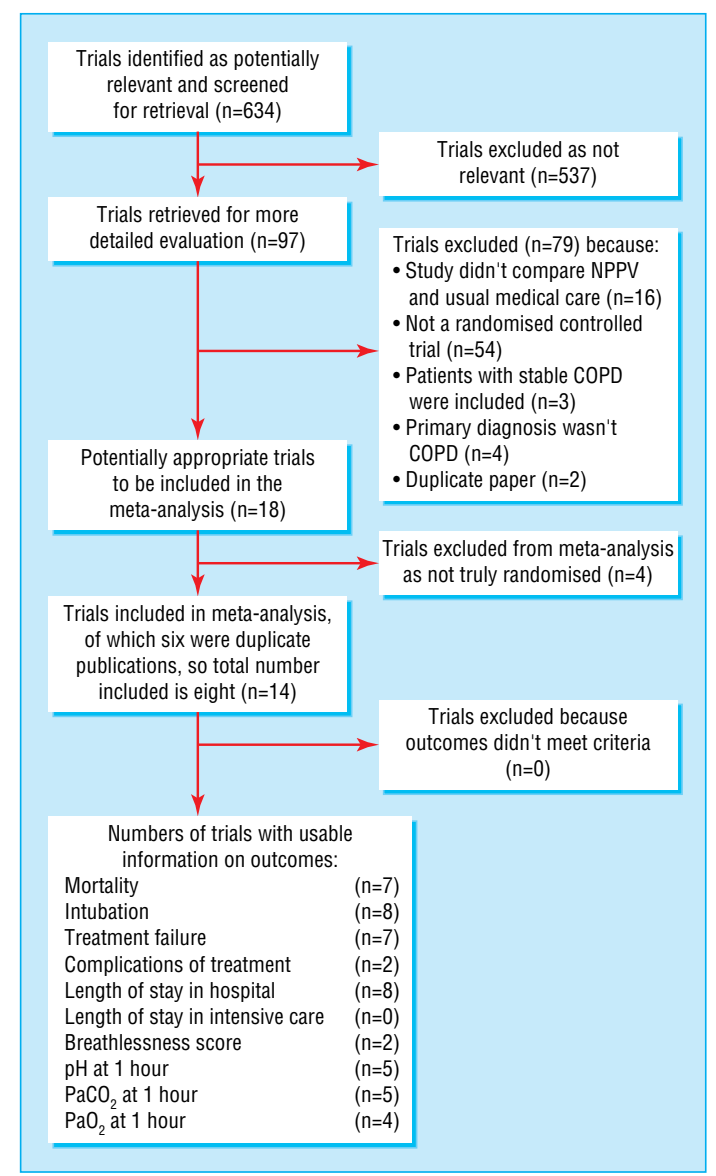

Fig 1 Process of inclusion of studies and useable information

biotics, bronchodilators, steroids, respiratory stimulants, and other suitable interventions (for example, diuretics and methylxanthines) but could not include treatment with NPPV.

Types of trials and participants-We considered randomised controlled clinical trials of any duration. We excluded trials where patients had a primary diagnosis of pneumonia, weaning trials, trials whose patients had other underlying pathologies, and trials where continuous positive airway pressure or endotracheal intubation preceded recruitment. All patients entered into the trials had to have an acute

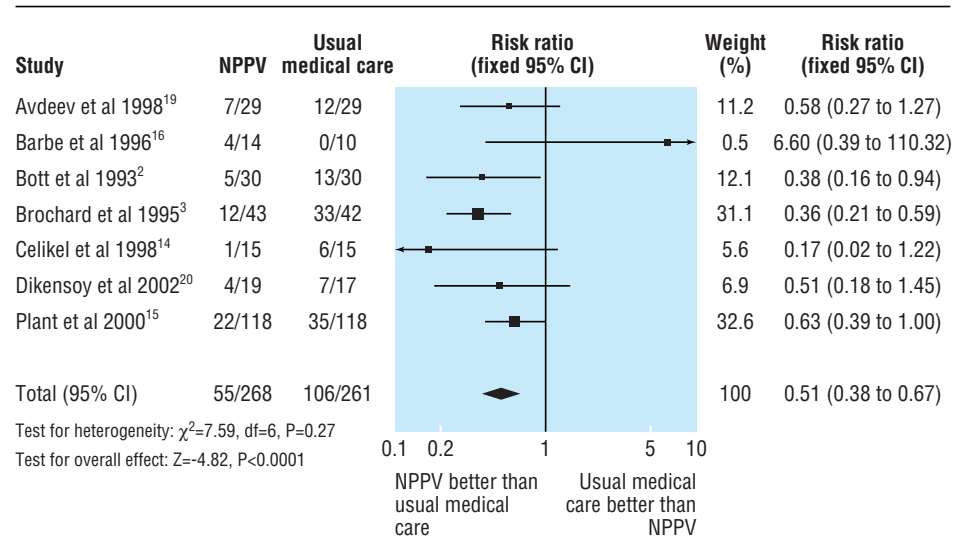

Fig 2 Risk of treatment failure (mortality, need for intubation, and intolerance) in seven studies of non-invasive positive pressure ventilation (NPPV) as an adjunct to usual medical care exacerbation of COPD and a baseline $\mathrm{PaCO}_{2}$ at admission of $>6 \mathrm{kPa}$.

\section{Identification and selection of trials}

We identified trials by searching the Cochrane Airways Group trials database, as well as other relevant databases (for example, the Science Citation Index, PubMed, the UK National Research Register), up to and including June 2002. No language restrictions were applied in the retrieval of citations.

We assessed the methodological quality of the trials by using the Cochrane approach to assessment of allocation concealment: all trials were scored as "adequate concealment" (grade A), "uncertain" (grade B), or "clearly inadequate concealment" (grade C).

\section{Data abstraction and analysis}

We used standard forms to abstract all data. Whenever possible we contacted an author of each trial included in the study to verify the accuracy of the abstracted data and to obtain further information. Review Manager version 4.1 (Cochrane Collaboration software) was used to combine data from the trials. Weighted mean differences (and 95\% confidence intervals) were used to pool data in continuous variables. For dichotomous variables, relative risks (and 95\% confidence intervals) were calculated. The number needed to treat (and 95\% confidence interval) was calculated in an internet based program called Visual Rx (www.nntonline.net). We used the DerSimonian and Laird method to test for heterogeneity among pooled estimates; results were considered significant at the $\mathrm{P}<0.05$ level. Where heterogeneity was present, the fixed effects model was used to report results; otherwise the random effects model was used. If there were sufficient numbers of studies for a particular outcome, and it was heterogeneous, we investigated it on the basis of study quality, duration of NPPV, type of NPPV, and type of mask used to administer NPPV. We also planned funnel plots to detect publication bias.

An intention to treat analysis was used in all studies except one, which we excluded from sensitivity analyses. ${ }^{16}$ We considered it important that studies use an intention to treat analysis, as there is anecdotal evidence that some patients drop out or withdraw after randomisation and at the initiation of treatment, because of the discomfort of NPPV.

\section{Results}

Figure 1 summarises the search for trials and reasons for exclusion, as well as the numbers of the eight trials included in the review with usable information on particular outcomes. ${ }^{23}$ 14-17 1920

\section{Methodological quality of included studies}

According to the Cochrane system for grading concealment of allocation, seven studies were grade $\mathrm{A}^{231415171920}$ and one was grade B. ${ }^{16}$ The seven grade A studies all used the same method for concealing treatment allocation: a randomly generated sequence of treatment allocation, contained in sealed envelopes. As all studies were of good methodological quality, it is unlikely that the quality of the studies would influence heterogeneity tests or the overall results. 


\section{Efficacy variables}

We defined treatment failure as the combination of mortality, need for intubation, and intolerance to the allocated treatment. Data from seven of the studies showed that NPPV resulted in a significantly lower risk of treatment failure (relative risk 0.51), compared with usual medical care, with a number needed to treat for NPPV to have a benefit of five (figure 2, table 1)..$^{314-16} 1920$ NPPV significantly reduced the risk of mortality (relative risk 0.41 ), with a number needed to treat of eight (figure 3, table 1). The risk of endotracheal intubation was more than halved with NPPV, and for every five patients treated with NPPV one patient would avoid intubation (figure 4, table 1). NPPV also reduced complications of treatment and length of stay in hospital (tables 1 and 2). NPPV significantly improved $\mathrm{pH}, \mathrm{PaCO}_{2}$, and respiratory rate within one hour of initiation (figure 5 , table 2).

\section{Discussion}

This systematic review shows a clear benefit of NPPV as an adjunct treatment to usual medical care in the management of patients admitted to hospital with respiratory failure secondary to an acute exacerbation of COPD. NPPV with usual medical care significantly reduces mortality, endotracheal intubation, treatment failure, complications, length of hospital stay, and blood gas tensions.

Although NPPV reduces the need for intubation, in some patients NPPV will fail, and it is essential that a decision be made with the patient on what should be done in this eventuality. Patients for whom NPPV eventually fails, despite initial tolerance and effectiveness of the treatment, need to be distinguished from patients who cannot tolerate it at all. An uncontrolled study of these "late failures" suggests a poor outcome regardless of whether the patient is intubated or continues to receive NPPV. ${ }^{21}$

NPPV reduced the length of stay in hospital by more than three days, and length of stay in hospital did not differ between intensive care units and medical wards. This finding has important resource implications, given the costs of and pressure on intensive care in the United Kingdom. However, if NPPV is to be used outside the intensive care unit (for example, specialist respiratory wards), it is important that staff are fully trained in the treatment and that monitoring facilities are in place. It is also important that there is 24 hour cover by appropriately qualified members of the medical team.

The number of complications associated with treatment was significantly lower with NPPV, with an overall risk reduction of $68 \%$. Almost all of the excess complications occurred because of intubation, suggesting that avoidance of intubation is the major benefit of NPPV.

Acidosis is an important prognostic factor for survival after respiratory failure in COPD, and thus early correction of acidosis is an essential goal of treatment. ${ }^{5}$ This review has shown that NPPV significantly improves $\mathrm{pH}, \mathrm{PaCO}_{2}$, and respiratory rate within the first hour. The improvement in $\mathrm{pH}$ associated with the fall in $\mathrm{PaCO}_{2}$ indicates an improvement in respiratory failure. A previous study of patients with respiratory failure secondary to exacerbations of COPD showed reductions in respiratory rate and transdiaphragmatic
Table 1 Effects of non-invasive positive pressure ventilation as an adjunct to usual medical care, compared with usual care alone: overall results of the review for dichotomous outcome measures

\begin{tabular}{|c|c|c|c|c|}
\hline Outcome & $\begin{array}{l}\text { Number of studies } \\
\text { contributing data }\end{array}$ & $\begin{array}{c}\text { Total number of } \\
\text { patients }\end{array}$ & $\begin{array}{l}\text { Relative risk } \\
(95 \% \mathrm{Cl})\end{array}$ & $\begin{array}{c}\text { Number needed to } \\
\text { treat }(95 \% \mathrm{Cl})\end{array}$ \\
\hline Treatment failure & $7^{2314-161920}$ & 529 & 0.51 (0.38 to 0.67$)$ & 5 (4 to 7$)$ \\
\hline Mortality & $7^{2314-161920}$ & 523 & $0.41(0.26$ to 0.64$)$ & $8(6$ to 13$)$ \\
\hline Intubation & $8^{2314-171920}$ & 546 & $0.42(0.31$ to 0.59$)$ & 5 (4 to 7$)$ \\
\hline Complications & $2^{319}$ & 143 & $0.32(0.18$ to 0.56$)$ & 3 (2 to 4$)$ \\
\hline
\end{tabular}

Table 2 Effects of non-invasive positive pressure ventilation as an adjunct to usual medical care, compared with usual care alone: overall results of the review for continuous outcome measures

\begin{tabular}{|c|c|c|c|}
\hline Outcome & $\begin{array}{l}\text { Number of studies } \\
\text { contributing data }\end{array}$ & $\begin{array}{l}\text { Total number of } \\
\text { patients }\end{array}$ & $\begin{array}{l}\text { Weighted mean } \\
\text { difference }(95 \% \mathrm{Cl})\end{array}$ \\
\hline \multicolumn{4}{|l|}{ Length of stay in hospital (days): } \\
\hline Trials in intensive care units & $3^{31417}$ & 138 & $-3.28(-6.09$ to -0.67$)$ \\
\hline Trials in wards & $5^{215161920}$ & 408 & $-3.20(-4.51$ to -1.89$)$ \\
\hline Total & $8^{2314-171920}$ & 546 & $-3.24(-4.42$ to -2.06$)$ \\
\hline $\begin{array}{l}\text { Respiratory rate (breaths per minute) } \\
\text { at } 1 \text { hour }\end{array}$ & $5^{314151920}$ & 380 & $-3.08(-4.26$ to -1.89$)$ \\
\hline $\mathrm{pH}$ at 1 hour & $5^{23141520}$ & 408 & $0.03(0.02$ to 0.04$)$ \\
\hline $\mathrm{PaCO}_{2}(\mathrm{kPa})$ at 1 hour & $5^{23141520}$ & 408 & $-0.40(-0.78$ to -0.03$)$ \\
\hline $\mathrm{PaO}_{2}(\mathrm{kPa})$ at 1 hour & $4^{231520}$ & 378 & $0.27(-0.26$ to 0.79$)$ \\
\hline
\end{tabular}

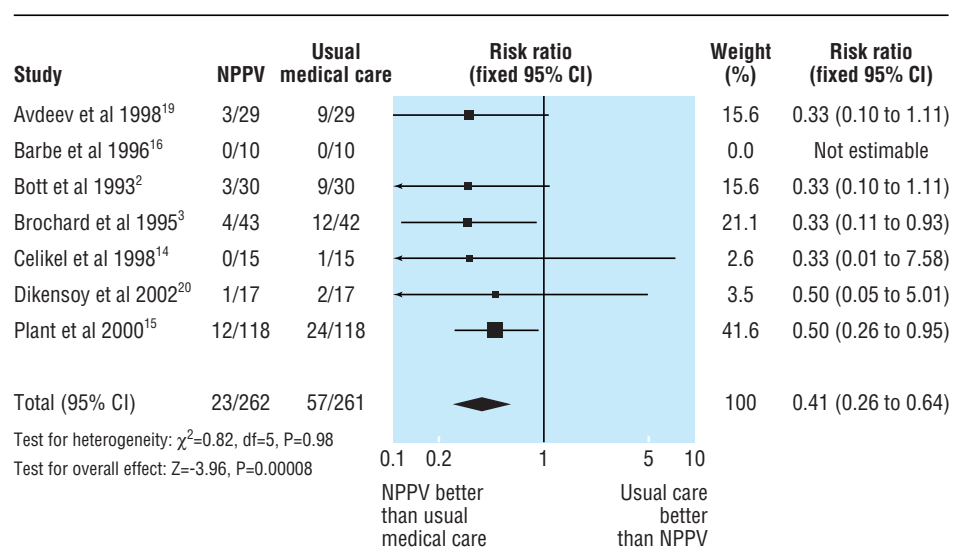

Fig 3 Mortality in seven studies of non-invasive positive pressure ventilation (NPPV) as an adjunct to usual medical care

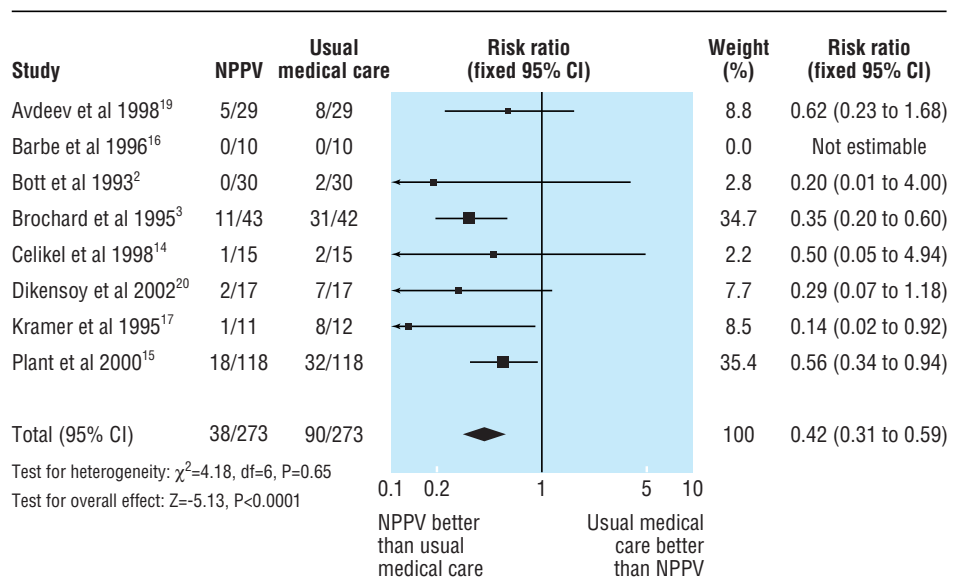

Fig 4 Risk of endotracheal intubation in eight trials of non-invasive positive pressure ventilation (NPPV) as an adjunct to usual medical care

activity, with increases in tidal volume and minute ventilation during NPPV. ${ }^{22}$ Thus, NPPV not only improves 


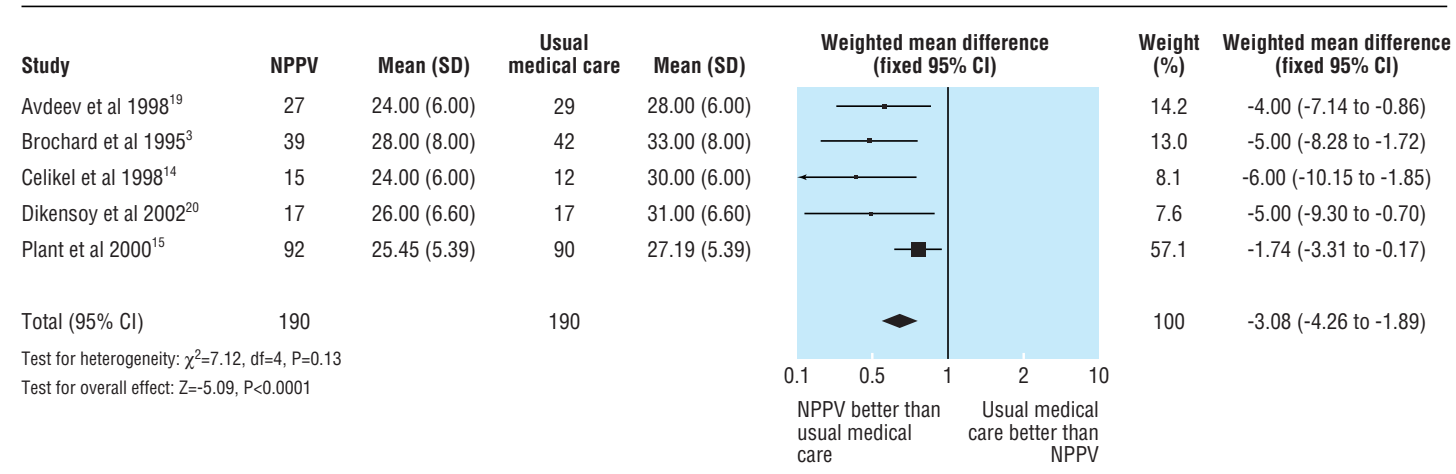

Fig 5 Respiratory rate (breaths per minute) in five trials of non-invasive positive pressure ventilation (NPPV) as an adjunct to usual medical care

gas exchange but also facilitates respiratory muscle rest, reducing the work of respiratory muscles in respiratory failure, and hence allowing the respiratory muscles to recover and conventional treatments to work.

\section{Limitations of the review}

Publication bias is possible, in that by missing unpublished or negative trials we may have overestimated the beneficial effect of NPPV. However, our comprehensive, systematic search strategy of the literature would minimise any biases. We are confident that most research in this field was identified. We further minimised bias by using two independent reviewers, with clearly defined written inclusion and exclusion criteria for the selection of studies. The small number of studies meant that a funnel plot analysis for the detection of publication bias was meaningless. Also, the usefulness of funnel plots for this purpose is limited by their moderately low sensitivity.

In none of the studies included in this review was treatment blinded, because of the practical difficulties of "sham" ventilation. However, in three of the studies investigators making clinical management decisions were unaware of which treatment arm a patient was in until after ventilation began. ${ }^{2}{ }^{19}$ In two studies the decision to intubate was not made by the study investigators. ${ }^{14}{ }^{17}$ In another study predefined criteria were used to determine when to intubate patients in cases of failure of NPPV ${ }^{15}$ In one study there was no indication as to the protocol for intubation and treatment failure. ${ }^{16}$ Therefore, we cannot be certain that bias in patient management did not influence the study outcomes.

The data at one hour would not necessarily include all patients who were started on treatment, as treatment may have failed (for example, intubation was necessary or the patient died) before the one hour time point. Therefore, we may have underestimated the difference between the two groups in changes in $\mathrm{pH}$, arterial blood gas tensions, and respiratory rate.

\section{Conclusions}

Despite the limitations, this review has shown convincing evidence from good quality, randomised controlled trials that NPPV is an effective adjunct to usual medical care in the management of respiratory failure secondary to acute exacerbations of COPD. Trialling NPPV should be considered early in the course of respiratory failure and before severe acidosis ensues, to avoid endotracheal intubation and treatment failure and to

\section{What is already known on this topic}

Prospective studies, especially the larger studies, have shown that non-invasive positive pressure ventilation (NPPV) reduces the need for intubation, improves survival, and reduces complications in patients with respiratory failure resulting from exacerbation of chronic obstructive pulmonary disease (COPD)

A previous meta-analysis showed NPPV to be an effective intervention, including for acute exacerbations of COPD, but some studies in this meta-analysis contained mixed groups of patients and were not of good quality

\section{What this study adds}

Evidence from good quality, randomised controlled trials shows that NPPV is an effective treatment for acute exacerbations of COPD

NPPV should be considered early in the course of respiratory failure and before severe acidosis ensues, to avoid the need for endotracheal intubation and reduce mortality in patients with COPD

reduce mortality. Further studies are needed to evaluate the appropriate selection of patients and to find the best level and schedule of ventilation.

We thank the members of the Cochrane Airways Group based at St George's Hospital Medical School, London. We also thank authors of studies who responded to requests for further data. ${ }^{2} 15171920$

Contributors: FSFR and JAW revised the original review protocol that was published in 1996 in the Cochrane Library. FSFR and JVL searched for trials and abstracted and analysed the data from the included trials. FSFR prepared the manuscript, with input from JVL, JAW, and MWE. FSFR revised the manuscript for resubmission and is the guarantor for the paper.

Funding: FSFR is funded by the Netherlands Asthma Foundation. JVL was funded by a British Lung Foundation project grant.

Competing interests: JAW has received educational grant support from Respironics, one of the manufacturers of nasal ventilators. MWE has received an honorarium for lecturing from Respironics, has been lent ventilators for studies from ResMed and Breas, and has had a contribution from ResMed towards the salary of a research nurse.

1 Ambrosino N, Foglio K, Rubini F, Clini E, Nava S, Vitacca M. Non-invasive mechanical ventilation in acute respiratory failure due to chronic 
obstructive pulmonary disease: correlates for success. Thorax 1995;50:755-7

2 Bott J, Carroll MP, Conway JH, Keilty SEJ, Ward EM, Brown AM, et al. Randomised controlled trial of nasal ventilation in acute ventilatory failure due to chronic obstructive airways disease. Lancet 1993;341:1555-7.

3 Brochard L, Mancebo J, Wysocki M, Lofaso F, Conti G, Rauss A, et al. Noninvasive ventilation for acute exacerbations of chronic obstructive pulmonary disease. N Engl J Med 1995;333:817-22.

4 Foglio C, Vitacca M, Quadri A, Scalvini S, Marangoni S, Ambrosino N. Acute exacerbations in severe COLD patients. Treatment using positive pressure ventilation by nasal mask. Chest 1992;101:1533-8.

5 Jeffrey AA, Warren PM, Flenley DC. Acute hypercapnic respiratory failure in patients with chronic obstructive lung disease: risk factors and use of guidelines for management. Thorax 1992;47:34-40.

6 Brochard L, Rauss A, Benito S, Conti G, Mancebo J, Rekik N, et al. Comparison of three methods of gradual withdrawal from ventilatory support during weaning from mechanical ventilation. Am J Respir Crit Care Med 1994;150:896-903

7 Esteban A, Frutos F, Tobin MJ, Alia I, Solsona JF, Valverdu I, et al. A comparison of four methods of weaning patients from mechanical ventilation. Spanish Lung Failure Collaborative Group. $N$ Engl J Med 1995;332:345-50.

8 Guerin C, Girard R, Chemorin C, De Varax R, Fournier G. Facial mask noninvasive mechanical ventilation reduces the incidence of nosocomial pneumonia. A prospective epidemiological survey from a single ICU. Intensive Care Med 1997;23:1024-32.

9 Fagon JY, Chastre J, Hance A, Montravers P, Novara A, Gibert C. Nosocomial pneumonia in ventilated patients: a cohort study evaluating attributable mortality and hospital stay. Am J Med 1993;94:281-7.

10 Kramer B. Ventilator-associated pneumonia in critically ill patients. An Intern Med 1999;130:1027-8.

11 Nourdine K, Combes P, Carton MJ, Beuret P, Cannamela A, Ducreux JC. Does noninvasive ventilation reduce the ICU nosocomial infection risk A prospective clinical survey. Intensive Care Med 1999;25:567-73.

12 British Thoracic Society Standards of Care Committee. Non-invasive ventilation in acute respiratory failure. Thorax 2002;57:192-211.

13 Meduri GU, Conoscenti CC, Menashe P, Nair S. Noninvasive face mask ventilation in patients with acute respiratory failure. Chest 1989;95:865-
14 Celikel T, Sungur M, Ceyhan B, Karakurt S. Comparison of noninvasive postitive pressure ventilation with standard medical therapy in hypercapnic acute respiratory failure. Chest 1998;114:1636-42.

15 Plant PK, Owen JL, Elliott MW. Early use of non-invasive ventilation for acute exacerbations of chronic obstructive pulmonary disease on general respiratory wards: a multicentre randomised controlled trial. Lance 2000;355:1931-5.

16 Barbe R, Togores B, Rubi M, Pons S, Maimo A, Agusti AGN. Noninvasive ventilatory support does not facilitate recovery from acute respiratory failure in chronic obstructive pulmonary disease. Eur Respir $J$ 1996;9:1240-5

17 Kramer N, Meyer TJ, Meharg J, Cece RD, Hill NS. Randomized, prospective trial of noninvasive positive pressure ventilation in acute respiratory failure. Am J Respir Crit Care Med 1995;151:1799-806.

18 Soo Hoo GW, Santiago S, Williams AJ. Nasal mechanical ventilation for hypercapnic respiratory failure in chronic obstructive pulmonary disease: determinants of success and failure. Crit Care Med 1994;22:1253-

19 Avdeev SN, Tretyakov AV, Grigoryants RA, Kutsenko MA, Chuchalin AG [Noninvasive positive airway pressure ventilation: role in treating acute respiratory failure caused by chronic obstructive pulmonary disease.] Anesteziol Reanimatol 1998;May-Jun:45-51. (In Russian.)

20 Dikensoy O, Ikidag B, Filiz A, Bayram N. Comparison of non-invasive ventilation and standard medical therapy in acute hypercapnic respiratory failure: a randomised controlled trial at a tertiary health centre in SE Turkey. Int J Clin Pract 2002;56:85-8.

21 Moretti M, Cilione C, Tampieri A, Fracchia C, Marchioni A, Nava S. Incidence and causes of non-invasive mechanical ventilation failure after initial success. Thorax 2000;55:819-25.

22 Brochard L, Isabey D, Piquet J, Amaro P, Mancebo J, Messadi AA, et al. Reversal of acute exacerbations of chronic obstructive lung disease by inspiratory assistance with a face mask. N Engl J Med 1990;323:1523-30.

(Accepted 16 October 2002) 